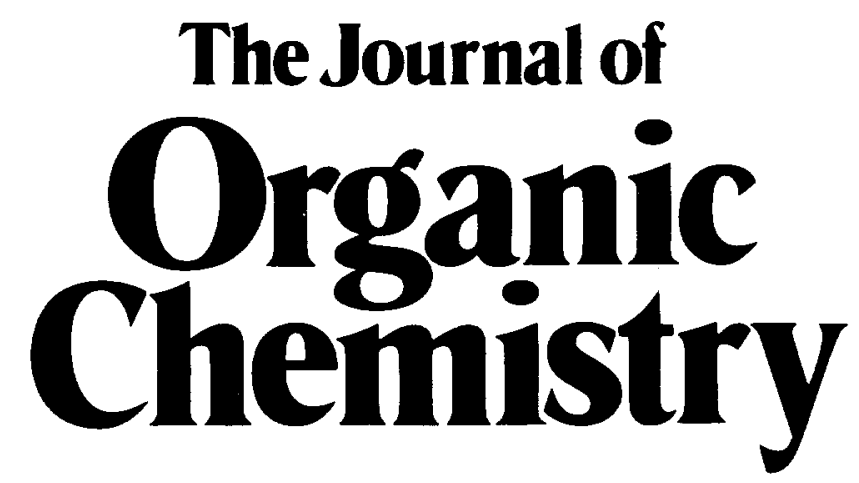

VOLUME 57, NUMBER 4

FEBRUARY 14, 1992

(c) Copyright 1992 by the American Chemical Society

\title{
Communications
}

\section{Synthesis of Allylazo Compounds by Reactions of Aryldiazonium Salts with Allylsilanes}

\author{
Herbert Mayr ${ }^{*, \dagger}$ and Klaus Grimm \\ Institut für Chemie der Medizinischen Universität zu Lübeck, Ratzeburger Allee 160, D-2400 Lübeck, Germany
}

Received September 27, 1991

Summary: Aryldiazonium tetrafluoroborates react with allylsilanes to yield allylazo compounds. If the allylic carbon attached to the azo group carries hydrogen, tautomerization with formation of hydrazones takes place.

The coupling of aryldiazonium ions with arylamines and phenols, discovered by Griess in $1858,{ }^{1}$ has been one of the most important reactions in industrial chemistry for more than a century. ${ }^{2}$ Among the aliphatic C-nucleophiles previously reported to react with diazonium ions, $\mathrm{CH}$ acidic compounds, ${ }^{3 a}$ enol ethers, ${ }^{3 b}$ enamines, ${ }^{3 c}$ and 1,3 dienes ${ }^{3 \mathrm{~d}}$ are the most important ones. Marxmeier and Pfeil have found that the 2,4-dinitrobenzenediazonium ion 1a also reacts with ordinary alkenes, often with cleavage of the original CC double bond as shown in Scheme I. ${ }^{4}$

Though allylsilanes have been combined with a manifold of electrophiles, ${ }^{5}$ reactions with diazonium ions have not yet been reported. Since the nucleophilicity of allyltrimethylsilane is similar to that of those alkenes, ${ }^{6}$ which are known to be susceptible to electrophilic attack by 1a, the electrophilicity of la should also be sufficient for a reaction with allylsilanes.

Combination of the $\gamma, \gamma$-disubstituted allylsilanes $2 \mathrm{a}-2 \mathrm{~g}$ with 2,4-dinitrobenzenediazonium tetrafluoroborate $1 \mathrm{a}$ in acetonitrile gives the allylazo compounds $3 \mathrm{a}-3 \mathrm{~g}$ in $38-94 \%$ yields (Table I) ${ }^{7}$ This reaction thus provides a straightforward access to allylazo compounds, which are of interest as precursors to allyl radicals. ${ }^{8}$ Representatives of this class of compounds have previously been synthesized by treatment of sulfamides (from allylamines and $N$-sulfonylaniline) with $\mathrm{NaOCl}$ and $\mathrm{NaOH}^{88}$ or by sigmatropic rearrangements of diazenes, which have been generated by oxidation of $N$-allyl- $N$-arylhydrazines. ${ }^{9}$

${ }^{\dagger}$ Present address: Institut für Organische Chemie der Technischen Hochschule Darmstadt, Petersenstr. 22, W-6100 Darmstadt, Germany.

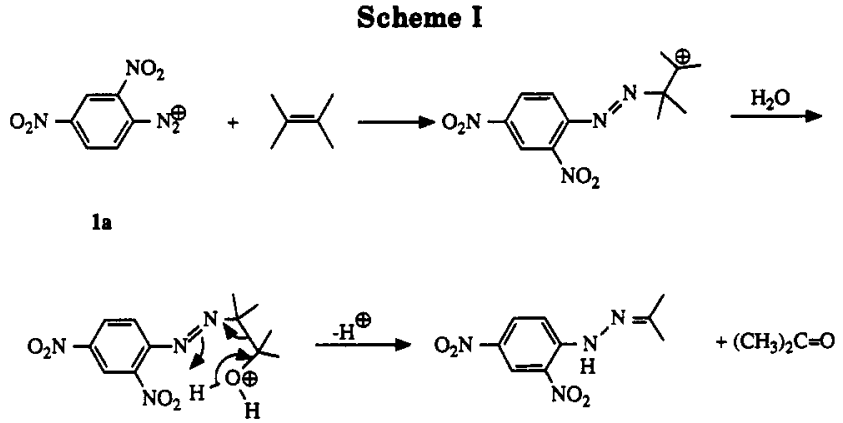

Scheme II
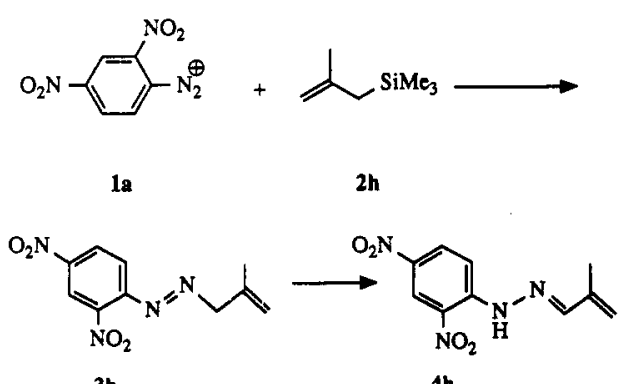

$3 \mathrm{~h}$

4h

The reaction of methallyltrimethylsilane $2 \mathrm{~h}$ with $\mathrm{la} \mathrm{BF}_{4}^{-}$ initially yields the crystalline allylazo compound $3 \mathrm{~h}$, which

(1) Griess, P. Liebigs Ann. Chem, 1858, 106, 123.

(2) (a) Szele, I.; Zollinger, H. Top. Curr. Chem. 1983, 112, 1. (b) Hegarty, A. F. In The Chemistry of Diazonium and Diazo Groups; Patai, S., Ed.; Wiley: Chichester, 1978; p 511. (c) Schündehütte, K. H. Methoden der Organischen Chemie (Houben-Weyl-Müller); Thieme: Stuttgart, 1965; Vol. X/3, p 213. (d) Saunders, K. H.; Allen, R. L. M. Aromatic Diazo Compounds; Edward Arnold: London, 1983.

(3) (a) Parmerter, S. M. Org. React. 1959, 10, 1. (b) Terent'ev, A. P.; Jagorsvkii, V. A. Zh. Obshch. Khim. 1956, 26, 211. (c) Crary, J. W.; Quayle, O. R.; Lester, C. T. J. Am. Chem. Soc. 1956, 78, 5584. (d) Huisgen, R.; Bronberger, F. Tetrahedron Lett. 1984, 25, 57. (e) Huisgen, R.; Bronberger, F. Tetrahedron Lett. 1984, 25, 61. 
Table I. Allylazo Compounds from $\gamma, \gamma$-Disubstituted Allylsilanes 2 and 2,4-Dinitrobenzenediazonium Tetrafluoroborate la

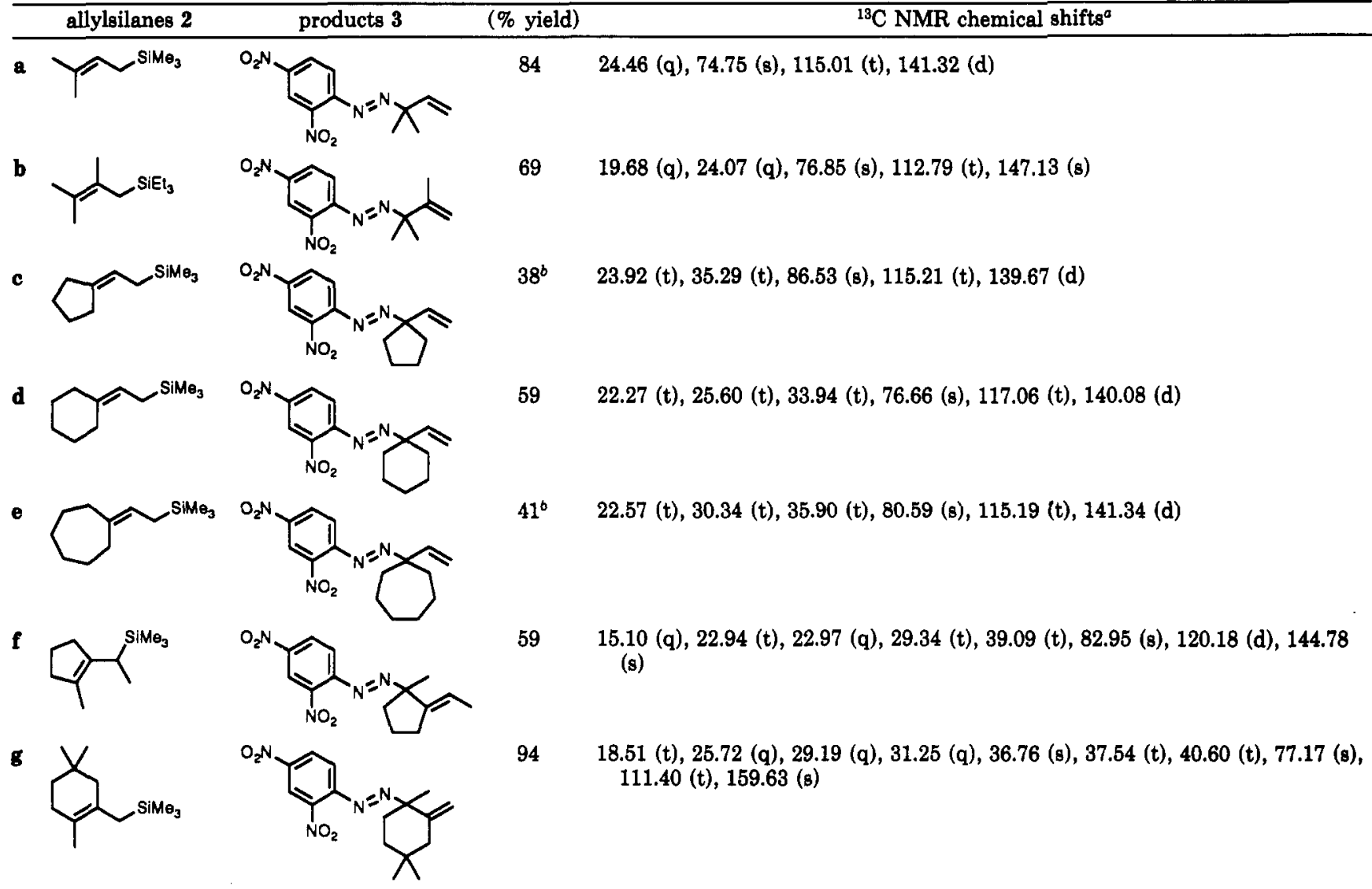

${ }^{\circ}$ Aryl-C: C-1 $\delta=149.96-150.43$ (s), C-2 $\delta=144.51-144.81$ (s), C-3 $\delta=120.24-120.51$ (d), C-4 $\delta=147.01-147.22$ (s), C-5 $\delta=128.30-128.42$ (d), C-6 $\delta=120.39-121.05$ (d). ${ }^{b}$ Unidentified hydrazones were also formed.

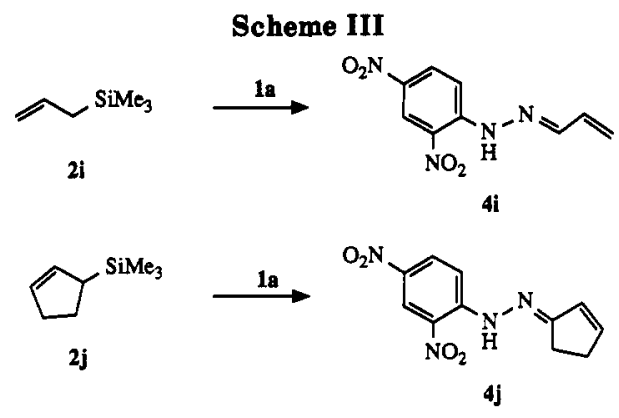

has been stored in the dark at $-20^{\circ} \mathrm{C}$ for several months. At room temperature, rearrangement to the hydrazone $4 h$

(4) Marxmeier, H.; Pfeil, E. Chem. Ber. 1964, 97, 53.

(5) (a) Weber, W. P. Silicon Reagents for Organic Synthesis; Springer-Verlag: Berlin, 1983. (b) Schinzer, D. Synthesis 1988, 263. (c) Fleming, I. In Comprehensive Organic Chemistry; Barton, D., Ollis, W. D., Eds.; Pergamon Press: Oxford, 1979; Vol. 3, p 541. (d) Sakurai, H. Pure Appl. Chem. 1985, 57, 1759. (e) Colvin, E. Silicon in Organic Synthesis; Butterworths: London, 1981.

(6) (a) Mayr, H.; Schneider, R.; Irrgang, B.; Schade, C. J. Am. Chem. Soc. 1990, 112, 4459. (b) Mayr, H. Angew. Chem. 1990, 102, 1415; Angew. Chem., Int. Ed. Engl. 1990, 29, 1371. (c) Hagen, G.; Mayr, H. J. Chem. Soc., Chem. Commun. 1989, 91. (d) Hagen, G.; Mayr, H. J. Am. Chem. Soc. 1991, 113, 4954

(7) Typical Procedure. Allylsilane $2 \mathrm{~b}(0.530 \mathrm{~g}, 2.67 \mathrm{mmol})$ was added to a suspension of 2,4-dinitrobenzenediazonium tetrafluoroborate $(0.500$ $\mathrm{g}, 1.77 \mathrm{mmol}$ ) in dry acetonitrile. The mixture was stirred until the diazonium salt dissolved. After addition of water, the mixture was extracted with two $10-\mathrm{mL}$ portions of $\mathrm{CH}_{2} \mathrm{Cl}_{2}$. The organic layers were dried over $\mathrm{CaCl}_{2}$ and evaporated. After purification of the residue by column chromatography (silica gel, $\mathrm{CH}_{2} \mathrm{Cl}_{2}$ /pentane, $70 / 30$ ) product $3 \mathrm{~b}$ was obtained and recrystallized from pentane: Orange plates $(0.340 \mathrm{~g}, 69 \%)$ mp $55-56{ }^{\circ} \mathrm{C}$
Table II. Relative Reactivities of the Allylsilanes $2 \mathrm{a}-2 \mathrm{~h}$ toward $\left(p-\mathrm{H}_{3} \mathrm{COC}_{6} \mathrm{H}_{4}\right) \mathrm{PhCH}^{+}$and Their Ability To React with Diazonium Ions

\begin{tabular}{ccccc}
\hline & & \multicolumn{3}{c}{ reaction with } \\
\cline { 2 - 5 } & $k_{\text {rel }}{ }^{a}$ & $\mathbf{1 a}$ & $\mathbf{1 b}$ & $\mathbf{1 c}$ \\
\hline $\mathbf{2 i}$ & 1 & + & - & - \\
$\mathbf{2 j}$ & 6.60 & + & - & - \\
$\mathbf{2 c}$ & $\sim 7$ & + & + & - \\
$2 \mathbf{d}$ & $\sim 7$ & + & + & - \\
$2 \mathbf{e}$ & $\sim 7$ & + & + & - \\
$\mathbf{2 a}$ & 7.92 & + & + & - \\
$2 \mathbf{h}$ & 508 & + & + & - \\
$\mathbf{2 f}$ & $\sim 10^{3}$ & + & + & - \\
$2 \mathbf{g}$ & $\sim 10^{3}$ & + & + & + \\
$\mathbf{2 b}$ & 1675 & + & + & +
\end{tabular}

${ }^{a}$ From ref $6 \mathrm{~d}$; estimates marked by the $\sim$ sign are based on $k_{\text {rel }}$ values of structurally analogous compounds.

is detectable after several hours. This tautomerization is very fast in chloroform solution (not purified from traces of $\mathrm{HCl}$ ) or during chromatography on silica gel. Analogously, the reaction of $2 \mathbf{i}$ and $2 \mathbf{j}$ with $1 \mathrm{a}$ yields the hydrazones $4 \mathbf{j}$ and $4 j$ as stable final products. Allylsilanes with one or two hydrogen atoms in $\gamma$-position thus can

(8) (a) Luedtke, A.; Meng, K.; Timberlake, J. W. Tetrahedron Lett. 1987, 28, 4255. (b) Adams, J. S. Burton, K. A. Andrews B. K. Weisman, R. B.; Engel, P. S. J. Am. Chem. Soc. 1986, 108, 7935. (c) Rossi, M.; Golden, D. M. J. Am. Chem. Soc. 1979, 101, 1230. (d) Crawford, R. J.; Takagi, K. J. Am. Chem. Soc. 1972, 94, 7406. (e) Crawford, R. J.; Hamelin. J.; Strehlke, B. J. Am. Chem. Soc 1971, 9.3, 3810. (f) Al-Sader, B. H.: Crawford, R. J. Can. J. Chem. 1970, 48, 2745. (g) Porter, N. A.; Iloff, P. M. J. Chem. Soc., Chem. Commun. 1971, 1575. 788 
oxidatively be desilylated by treatment with aryldiazonium ions.

Preliminary experiments showed that among the allylsilanes used in this work all but $2 \mathbf{i}$ and $2 j$ also react with the less electrophilic $p$-nitrobenzenediazonium ion $1 \mathrm{~b}$. The highly alkylated allylsilanes $2 \mathrm{~b}$ and $2 \mathrm{~g}$ even react with the unsubstituted benzenediazonium ion $1 \mathrm{c}$ to give $3 \mathrm{~b}^{\prime}$ and $3 \mathbf{g}^{\prime}$ in 51 and $74 \%$ yield, respectively. In accord with our previous report that allylstannanes are more nucleophilic than structurally analogous allylsilanes by several orders of magnitude, ${ }^{\text {d }}$ tri- $n$-butylprenylstannane also reacted with the parent benzenediazonium ion $1 \mathrm{c}$ to afford $49 \%$ of $3 \mathrm{a}^{\prime}$. Though the correlation between reactivities toward carbenium and diazonium ions does not seem to be perfect, Table II shows that the nucleophilicity scale developed with respect to diarylcarbenium ions ${ }^{6}$ also allows one to roughly predict the feasibility of electrophilic attack of

diazonium ions at allylsilanes.<smiles>[NH3+]C1[C+]C([N+](=O)[O-])C=C1</smiles>

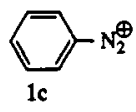<smiles>C=CC(C)(C)NNCc1ccccc1</smiles>

$3 \mathbf{a}^{\prime}$

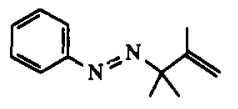

3b'

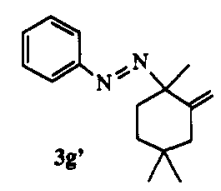

Registry No. 1a, 345-12-0; 1b, 456-27-9; 1c, 369-57-3; 2a, 18293-99-7; 2b, 64545-12-6; 2c, 83438-58-8; 2d, 63922-76-9; 2e, 138061-12-8; 2f, 138061-13-9; 2g, 138061-14-0; 2h, 18292-38-1; 2i, $762-72-1 ; 2 j, 14579-08-9$; 3a, 138061-15-1; 3a', 31928-42-4; 3b, 138061-16-2; 3b', 138061-17-3; 3c, 138061-18-4; 3d, 138061-19-5; 3e, 138061-20-8; 3f, 138061-21-9; 3g, 138061-22-0; 3', 138061-23-1.

\title{
(R)-1-Acetyl-5-isopropoxy-3-pyrrolin-2-one: A Versatile Chiral Dienophile from (S)-Malic Acid
}

\author{
Wim-Jan Koot, Henk Hiemstra,* and W. Nico Speckamp*
}

Department of Organic Chemistry, University of Amsterdam, Nieuwe Achtergracht 129, 1018 WS Amsterdam, The Netherlands

Received October 28, 1991

Summary: The title compound, readily prepared from $(S)$-malic acid, reacts as a Diels-Alder dienophile with several 1,3-dienes with excellent regio- and stereoselectivity without loss of enantiomeric purity. The synthesis of an enantiomerically pure intermediate in a projected synthesis of gelsemine is detailed.

Of the various ways to control the absolute stereochemistry of an intermolecular Diels-Alder reaction, the approach involving the use of an enantiomerically pure dienophile has proven to be most practicable. ${ }^{1}$ In this paper we wish to present the synthesis and utility of the chiral dienophile $(R)$-1-acetyl-5-isopropoxy-3-pyrrolin-2-one (1), which in essence can be viewed as an enantiomerically pure synthetic equivalent of maleimide. ${ }^{2}$<smiles>C[C@H](O)O[C@H]1C=CC(=O)N1C(N)=O</smiles>

1<smiles>C=C1C=CC(C)N1C(C)C</smiles>

2

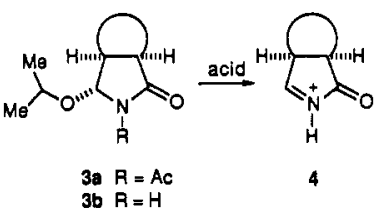

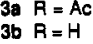

The choice for the structural features present in 1 was eventually made, when we had found that other $\Delta^{3}$ pyrrolin-2-ones such as $2^{3}$ were unsuitable for our purposes. The isopropoxy function at C-5 in 1 is meant to direct 1,3-dienes to react at the opposite face of the molecule to give $3 \mathbf{a} .{ }^{4}$ The significance of an alkoxy function at C-5

(1) For reviews, see: (a) Paquette, L. A. In Asymmetric Synthesis; Morrison, J. D., Ed.; Academic: New York, 1984; Vol. 3, Chapter 7. (b) Oppolzer, W. Angew. Chem., Int. Ed. Engl. 1984, 23, 876.

(2) For recent alternative approaches, see: (a) Arai, Y.; Matsui, M.; Koizumi, T.; Shiro, M. J. Org. Chem. 1991, 56, 1983. (b) Baldwin, S. W.; Greenspan, P.; Alaimo, C.; McPhail, A. T. Tetrahedron Lett. 1991, 32, 5877. For a chiral synthetic equivalent for maleic anhydride, see: (c) Feringa, B. L.; de Jong, J. C. J. Org. Chem. 1988, 53, 1125. (d) de Jong J. C.; Jansen, J. F. G. A.; Feringa, B. L. Tetrahedron Lett. 1990, 31, 3047

(3) The study of 2 originated from our work on the synthesis of the indole alkaloid peduncularine and will be described in a full paper; see: Klaver, W. J.; Hiemstra, H.; Speckamp, W. N. J. Am. Chem. Soc. 1989, $111,2588$.

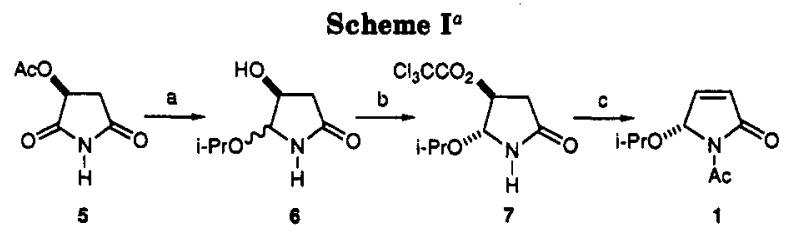

a Reagents and conditions: (a) (i) $\mathrm{LiBH}_{4}$ (1.0 equiv), THF, -20 $\rightarrow 0^{\circ} \mathrm{C}$, (ii) $\mathrm{H}_{2} \mathrm{SO}_{4}$ in i-PrOH (pH $=3$ ), $0{ }^{\circ} \mathrm{C} \rightarrow$ reflux, $55 \%$; (b) $\left(\mathrm{Cl}_{3} \mathrm{CCO}\right)_{2} \mathrm{O}$ (1.1 equiv), DMAP (1.1 equiv), $\mathrm{Et}_{2} \mathrm{O},-60^{\circ} \mathrm{C} \rightarrow \mathrm{rt}$, $86 \%$; (c) $\mathrm{Ac}_{2} \mathrm{O} /$ pyridine, DMAP (cat.), $0^{\circ} \mathrm{C} \rightarrow \mathrm{rt}, 85 \%$.

becomes apparent after removal of the $N$-acetyl function, as $3 \mathbf{b}$ is expected to allow the introduction of a variety of substituents via $N$-acyliminium intermediate $4 .{ }^{5}$ The presence of the $N$-acetyl function in 1 is required to prevent racemization and enhance the reactivity and regiochemical bias of the dienophile. ${ }^{6}$

The synthesis of $(R)-1$ is detailed in Scheme I. (S)-3Acetoxysuccinimide (5), readily prepared on large scale from $(S)$-malic acid, ${ }^{7}$ was regioselectively reduced with lithium borohydride in $\mathrm{THF}$ at $-20^{\circ} \mathrm{C}$. The crude reaction mixture was acidified with sulfuric acid. The solvent THF was then substituted for 2-propanol and the resulting mixture heated at reflux for $18 \mathrm{~h}$ to effect both isopropanolysis and transesterification, to give 6 as a $1: 4$

(4) For Diels-Alder additions to $\Delta^{3}$-pyrrolin-2-ones with carbon substituents at C-5, see: (a) Vedejs, E.; Campbell, J. B., Jr.; Gadwood, R. C.; Rodgers, J. D.; Spear, K. L.; Watanabe, Y. J. Org. Chem. 1982, 47, 1534. (b) Stork, G.; Nakahara, Y.; Nakahara, Y.; Greenlee, W. J. J. Am. Chem. Soc. 1978, 100, 7775. (c) Ohfune, Y.; Tamita, M. J. Am. Chem. Soc. 1982, 104, 3511. (d) Harkin, S. A.; Singh, O.; Thomes, E. J. J. Chem. Soc., Perkin Trans. 1 1984, 1489. (e) Ackermann, J.; Matthes, M.; Tamm, C. Helv. Chim. Acta 1990, 73, 122. (f) Meyers, A. I.; Busacca, C. A. Tetrahedron Lett. 1989, $30,6973$.

(5) For a review, see: Hiemstra, H.; Speckamp, W. N. In Comprehensive Organic Synthesis; Trost, B. M., Fleming, I., Eds; Pergamon: Oxford, 1991; Vol. 2, Chapter 4.5.

(6) (a) Vedejs, E.; Gadwood, R. C. J. Org. Chem. 1978, 43, 376. (b) Baker, J. T.; Sifniades, S. J. Org. Chem. 1979, 44, 2798. (c) Schmidlin, T.; Tamm, C. Helv. Chim. Acta 1980, 63, 121

(7) (a) Chamberlin, A. R.; Chung, Y. L. J. Am. Chem. Soc. 1983, 105, 3653. (b) Hart, D. J.; Yang, T.-K. J. Org. Chem. 1985, 50, 235. 